\title{
Experimental Study on Thermal Performance of Loop Heat Pipe with Flat-Rectangular Evaporator Under Gravity Assisted Condition
}

\author{
Phuoc Hien Huynh ${ }^{\mathrm{a},{ }^{*}}$, Kyaw Zin Htoo ${ }^{\mathrm{b}}$, Keishi Kariya ${ }^{\mathrm{c}}$, Akio Miyara ${ }^{\mathrm{d}, \mathrm{e}}$ \\ ${ }^{a}$ Graduate school of Science and Engineering, Saga University. Email: hphien@ hcmut.edu.vn \\ ${ }^{\mathrm{b}}$ Graduate school of Science and Engineering, Saga University. Email: kyawzinhtoo@gmail.com \\ cDepartment of Mechanical Engineering, Saga University. Email: kariya@me.saga-u.ac.jp \\ dDepartment of Mechanical Engineering, Saga University. Email: miyara@me.saga-u.ac.jp \\ e International Institute for Carbon-Neutral Energy Research, Kyushu University
}

\begin{abstract}
In company with extreme developments of electronic devices, there are some unavoidable challenges to the conventional cooling methods such as high heat dissipation, limitation of cooling space, reliable operation as well as saving energy consumption. Therefore, the necessity of studying on new or how to improve the existing technologies is undoubted. Among various methodologies, the loop heat pipe (LHP) whose operation principle base on phase changing process, can be considered as one of the potential solutions of modern electronics cooling. This paper introduces the experimental investigation on the thermal performance of a flat-rectangular evaporator LHP with sintered stainlesssteel wick when functioning under gravity assisted condition. Working fluid of this LHP was water. The present LHP could maintain stable operation in the range of heating power from $50 \mathrm{~W}$ to $520 \mathrm{~W}$ and keep the temperature on the heater's top surface at $85^{\circ} \mathrm{C}$, commonly recommended as the limitation temperature of electronics, when heating power reaches value $350 \mathrm{~W}\left(129.6 \mathrm{~kW} / \mathrm{m}^{2}\right)$. Besides, when turning the heater off, it took about 15 minutes for the LHP to cool the heating block from $102^{\circ} \mathrm{C}$ to $37^{\circ} \mathrm{C}$. In addition, an assumption of the boiling heat transfer is introduced in this paper to explain the performance of evaporator at different heat flux conditions of the experiment.
\end{abstract}

Keywords: Boiling heat transfer; electronics cooling; gravity assisted condition; loop heat pipe; phase change

\section{Introduction}

In recent decades, the rapid developments in telecommunication and information technology led to the dramatic changes in the data center industry. One of the most changes is the gain of generated heat power and heat flux because of the increment of the components installed on one chip. While in the 1960s, there were about one thousand elements functioning on one chip, it is predicted that this number can reach 20 billion for the $1-\mathrm{cm}^{2}$ size chip 2020 [1]. It limits the utilization the present cooling methods such as air cooling or 1-phase cooling because of low cooling capacity. In addition, the existent of various new social networks, cloud computing technologies, the number of data centers increases years after years. For examples, it was recorded that in the United States, the number of data centers increased from 432 to 2094 units during the period 1998-

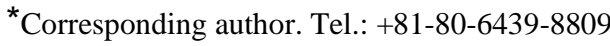

Saga, Japan, 840-0027
}

2010 [2]. As a result, there is the increased demand for electricity energy to operate these systems. Also mentioned in [2], in 2010 electrical energy consumed by data centers took $1.3 \%$ of total global using, and annual increment was predicted as high as 15 to $20 \%$. However, around $33 \%$ of them was used by the mechanical equipment functioning inside the thermal management systems or become useless energy [3]. In consequence, requirements of an effective modern cooling methodology are not only keeping the electronics operating stably under the safety temperature but also making them friendly with the environment by reduced electricity energy consumption.

From the above points, loop heat pipe (LHP), a novel catalog of the heat pipe, can be one of the potential candidates. In comparison with a normal heat pipe, LHP can transfer heat with the lower thermal resistance through the further distance because the liquid and vapor lines are separated together and there is no wick or capillary structure requested on the whole length of the liquid line, so reducing the total pressure drop along the loop [4]. The working fluid 
is circulated between evaporator and condenser by capillary forced or gravity force, so there is no work input to operate the pump or compressor as in the case of other two-phase cooling methods. It means that the both of electricity consumption and operating cost can be reduced while the lifespan and reliable operation become higher due to the reduction of mechanical components. When applied in the fields such as cooling the processors of the highperformance computers or data centers on earth, it is possible to arrange the position of the condenser to be higher than evaporator; as the result, heat transfer capacity of LHP can be increased significantly more than in the case of horizontal or anti-gravity operating condition.

Therefore, studying on the LHP operating under gravity assisted condition or loop thermosyphon has taken attention from different research groups. Ji Li et al. [5] conducted an experiment to investigate the startup and stable operation of LHP with a square-flat evaporator and grooved-sintered copper wick. From the measuring and observation results, they proposed two modes, boiling trigger mode and evaporation trigger mode to explain the different startup behavior of LHP for different heat loads. To more understand the effect of inventory on LHP performance, the research group of J. Xu et al. [6] made the flat cooper LHP with evaporator's cover made from polycarbonate. They made the conclusion that large inventory can prevent heat leak through the wick body but cause high-frequency temperature oscillation during startup as well as during operation period. One of the most recent studies was conducted by G. Zhou et al that focused on the two-phase flow characteristics of LHP with flat evaporator [7]. Their observation and measuring results show that boiling incipience depends slightly on the heat loads and nucleate boiling as well as thin film evaporation are the two-main heat transfer mechanisms inside their evaporator. Moreover, there are other studies on the wickless LHP or loop thermosyphon. Most of these studies try to modify the evaporator or change the working fluid to improve cooling capacity. A. Suzuki et al [8] introduced a LHP that applies the JEST (Jet Explosion Stream Technology) technology to enhance the heat transfer in the evaporator. In the studies conducted by C. Kondou et al [9] and H. He et al. [10], the heat transfer in the evaporator can be enhanced if the wettability characteristics of the boiling surface is modified appropriately. Indicated in [9], the super-hydrophilic surface could enhance the evaporator heat transfer when working fluid is volatile fluids such as R134a, R1234ze(Z), $\mathrm{R} 1234 z e(\mathrm{E})$. However, in the cases that working fluid is water, a mixed-wettability surface is suggested to eliminate the negative effect due to the boiling of water under subatmosphere pressure [10].

Although there are numerous studies on loop thermosyphon or LHP operating with the favorable gravitational condition, it still requires more research to simplify the structure of LHP, particularly evaporator to make the LHP become the commercialization state as normal heat pipe. In this study, a copper LHP with sintered stainless-steel wick was manufactured and investigated its thermal performance during startup, stable operational

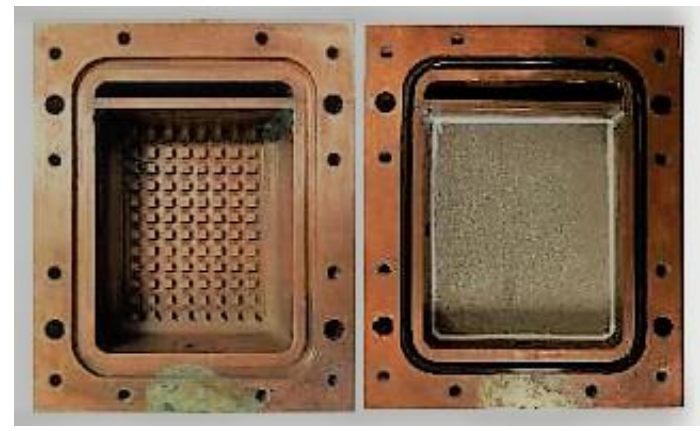

Figure 1. The evaporator without and with the stainless-steel wick

period as well as cooling performance under zero - heating power when functioning under gravity assisted condition. The different design of the present evaporator is the crossing groove or fin array was machined on the inner surface of the evaporator as shown in Fig. 1. This design can avoid machining the grooves on the wick surface that can damage or change the surface characteristics of the wick. Besides, it also guarantees the sufficient space for evaporation as well as paths for vapor flow out easily, so prevent vapor forming inside the wick. The evaporator cover is made of polycarbonate to observe the state of compensation chamber; therefore, water is selected as working fluid because of low operational pressure. Our experimental result indicate that this simple design of evaporator can satisfy the heat power generated from the future electronic device. Moreover, in this study, we assumed a theory of boiling heat transfer to explain the various performance of the evaporator with different heat flux values.

\section{Experimental Setup and Data Reduction}

\subsection{Experimental setup}

The schematic diagram of the experiment is described in Fig. 2. The evaporator was heated by four cartridge heaters that were inserted to the copper heating block. The magnitude of heating power was adjusted by the YAMABISHI MVS-520 Volt-slider and monitored on the YOKOGAWA WT230 digital power meter. On the other hand, the condenser was cooled by water whose inlet temperature and mass flow rate were set at $27.5{ }^{\circ} \mathrm{C}$ and $27 \mathrm{~kg} / \mathrm{h}$ respectively by the ADVANTEC LV-400 constant temperature circulator device. However, for determining the accurate value of heat flow rate from heating block to evaporator, the temperatures on the top surface of heating block as well as the bottom surface of evaporator, three $0.5 \mathrm{~mm}$-diameter thermocouples $T_{1}, T_{2}, T_{3}$ were attached into the heating block and another $1 \mathrm{~mm}$-diameter $T_{4}$ was inserted into evaporator base body as shown in Fig. 3 . Between the heating block and evaporator there was a thin layer of thermal conductivity grease that eliminates the thermal contact resistance. In addition, for understanding the state of circulation inside the LHP, four thermocouples including $T_{e o}, T_{c i}, T_{c o}$ and $T_{c c i}$ were inserted directly to path of the LHP at different locations such as outlet of evaporator, inlet of condenser, outlet of condenser, and inlet of 


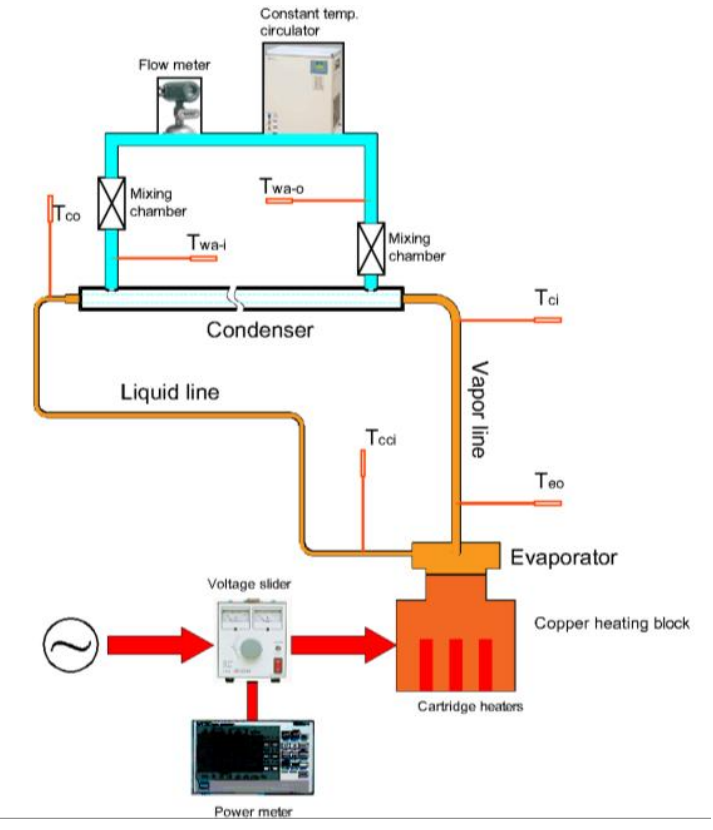

Figure 2. Schematic diagram of experiment

Table 1. Main parameters of LHP

\begin{tabular}{|c|c|}
\hline Heating block & \\
\hline Material & Copper \\
\hline Mass, kg & 4.36 \\
\hline \multicolumn{2}{|l|}{ Evaporator body } \\
\hline Material & Copper \\
\hline Length, mm & 80 \\
\hline Width, mm & 70 \\
\hline Height, $\mathrm{mm}$ & 24.5 \\
\hline Active area, $\mathrm{mm}^{2}$ & $60 \times 45$ \\
\hline \multicolumn{2}{|l|}{ Fin geometry } \\
\hline Cross area, $\mathrm{mm}^{2}$ & $2 \times 2$ \\
\hline Height, mm & 1.5 \\
\hline Fin pitch, $\mathrm{mm}$ & 4 \\
\hline \multicolumn{2}{|l|}{ Wick structure [11] } \\
\hline Material & Stainless steel \\
\hline Opening, $\mu \mathrm{m}$ & 63 \\
\hline Void ratio, \% & $36-48$ \\
\hline Bulk volume, $\mathrm{mm}^{3}$ & $50 \times 41 \times 5$ \\
\hline \multicolumn{2}{|l|}{ Vapor line } \\
\hline $\mathrm{OD} / \mathrm{ID}, \mathrm{mm}$ & $6.35 / 4.35$ \\
\hline Length, mm & 800 \\
\hline \multicolumn{2}{|l|}{ Condenser line } \\
\hline $\mathrm{OD} / \mathrm{ID}, \mathrm{mm}$ & $6.35 / 4.35$ \\
\hline Length, $\mathrm{mm}$ & 600 \\
\hline \multicolumn{2}{|l|}{ Liquid line } \\
\hline $\mathrm{OD} / \mathrm{ID}, \mathrm{mm}$ & $3.2 / 1.7$ \\
\hline Length, mm & 1300 \\
\hline Working fluid & Water \\
\hline
\end{tabular}

Table 2. Uncertainty values

\begin{tabular}{cc}
\hline & Uncertainty \\
\hline$T_{1}, T_{2}, T_{3}$ & $\pm 0.06^{\circ} \mathrm{C}$ \\
\hline$T_{4}$ & $\pm 0.07^{\circ} \mathrm{C}$ \\
\hline$T_{e o}$, & $\pm 0.06^{\circ} \mathrm{C}$ \\
\hline$T_{c i}$, & $\pm 0.06^{\circ} \mathrm{C}$ \\
\hline$T_{c o}, T_{c c i}$ & $\pm 0.1^{\circ} \mathrm{C}$ \\
\hline$T_{\text {wa-i, }}$ & $\pm 0.1^{\circ} \mathrm{C}$ \\
\hline$T_{\text {wa-o }}$ & $\pm 0.06^{\circ} \mathrm{C}$ \\
\hline$T_{a}$ & $\pm 0.16^{\circ} \mathrm{C}$ \\
\hline Mass flow meter & $0.18 \%$ of reading \\
\hline
\end{tabular}

compensation chamber respectively. In addition, heat released from condenser could be estimated by mass flow rate and different temperature of cooling water between inlet and outlet by MASSMAX MMM7150K flowmeters and two thermocouples $T_{w a-i}$ and $T_{w a-o}$. Table 1 lists the main specifications of the LHP, and the uncertainty of measurement devices are shown in Table 2 .

\subsection{Data reduction}

Heat flux $q$ and heat flow rate $Q$ flowing from the heating block to the evaporator

$$
\begin{aligned}
& q=k \frac{T_{1}-T_{2}}{\delta_{1}}=k \frac{T_{2}-T_{3}}{\delta_{1}}=k \frac{T_{1}-T_{3}}{2 \delta_{1}} \\
& Q=q A
\end{aligned}
$$

Temperature on the top surface of heating block $T_{s l}$ and bottom surface of evaporator $T_{s 2}$

$$
\begin{aligned}
& T_{s 1}=T_{1}-3 \frac{q \delta_{1}}{k}=T_{2}-2 \frac{q \delta_{1}}{k}=T_{3}-\frac{q \delta_{1}}{k} \\
& T_{s 2}=T_{4}+\frac{q \delta_{2}}{k}
\end{aligned}
$$

Total thermal resistance $R_{t}$, evaporator thermal resistance $R_{e}$, condenser thermal resistance $R_{c}$ and contact thermal resistance $R_{c t}$.

$$
\begin{aligned}
& R_{t}=\frac{T_{s 1}-T_{w a-i}}{q A} \\
& R_{e}=\frac{T_{s 2}-T_{e o}}{q A} \\
& R_{c}=\frac{T_{c i}-T_{w a-i}}{Q_{c}}
\end{aligned}
$$

With $Q_{c}$ is heat released at condenser

$$
Q_{c}=m_{w a} c_{p}\left(T_{w a-o}-T_{w a-i}\right)
$$




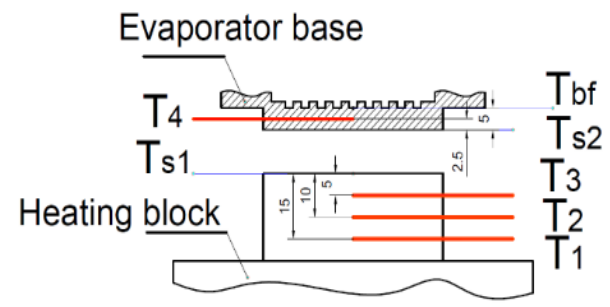

Figure 3. Temperature gradient measurement

$$
R_{c t}=\frac{T_{s 1}-T_{s 2}}{q A}
$$

Evaporator heat transfer coefficient $h_{e}$

$$
h_{e}=\frac{q}{T_{b f}-T_{e o}}
$$

In the Eq. 10, $T_{e o}$ is considered as saturated temperature inside evaporator. As being described in Fig. 3, $T_{b f}$ is the temperature at the base of the fin which can be estimated by the following equation

$$
T_{b f}=T_{4}-\frac{q \delta_{2}}{k}
$$

\section{Results and Discussion}

During the experiment, the heating power was adjusted in the range from $50 \mathrm{~W}$ to $520 \mathrm{~W}$. The upper limitation is the maximum capacity of the Volt-slider. The performance of the loop heat pipe could be considered as stable characteristic if the temperatures $T_{1}, T_{2}, T_{3}, T_{4}$ could maintain stably more than 30 minutes.

\subsection{Startup characteristics of the LHP}

Figures 4, 5, and 6 demonstrate the change of temperature inside the heater $T_{1}$, outlet of evaporator $T_{e o}$, inlet of condenser $T_{c i}$, outlet of condenser $T_{c o}$ and inlet of compensation chamber $T_{c c i}$ during the startup of this LHP under different heating powers such as $50 \mathrm{~W}, 135 \mathrm{~W}$ and $270 \mathrm{~W}$, respectively. The startup period could be divided into two stages. The first stage is the beginning of evaporation or value of $T_{e o}$ starting to increase while the ending of the second stage is indicated by the sudden increase of $T_{c i}$ as well as a slight raise of $T_{c o}$ and $T_{c i}$. It means that the hot vapor from evaporator entered the condenser, condensed into liquid, then returned the compensation chamber or the circulation happened totally. Generally, the time for the LHP to startup reduced from 12 mins to $2.5 \mathrm{mins}$ when heating power increased from $50 \mathrm{~W}$ to $270 \mathrm{~W}$. In addition, at the end of startup period, there was the presence of temperature overshoot of $T_{e o}$. Its magnitude also reduced with the increase of heating power. Moreover, in the cases of $125 \mathrm{~W}$ and $270 \mathrm{~W}, T_{e o}$ increases suddenly in the second stage of startup while it increased slowly at heating power of $50 \mathrm{~W}$. This phenomenon indicates that under low heating power condition, the grooves and lower part of vapor line of the LHP was flooded with liquid phase that prevented the vapor from flowing out the evaporator to enter the condenser. This is also the reason that caused the temperature overshoot happens. When the heating power increased, the combination of high evaporation rate and reduction of the liquid phase in the vapor line made the duration of second stage and magnitude of temperature overshoot reduce significantly; consequently, the LHP could startup faster.

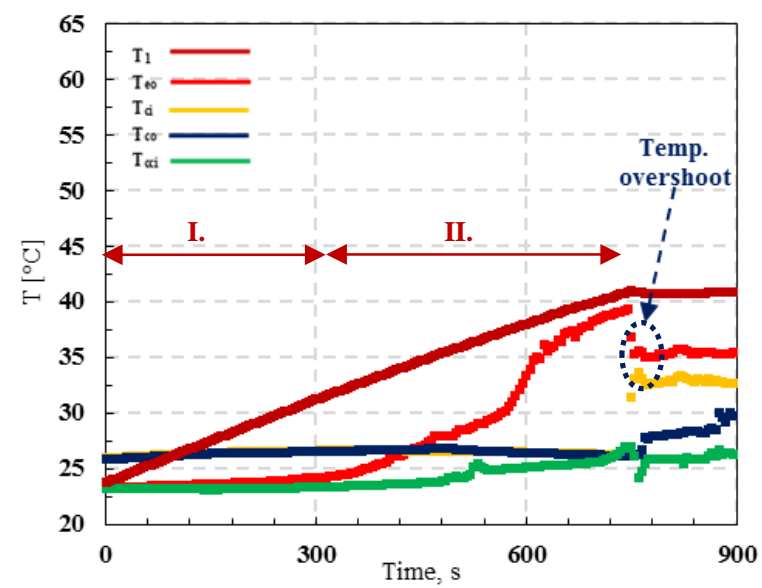

Figure 4. Startup of LHP when heating power was 50W

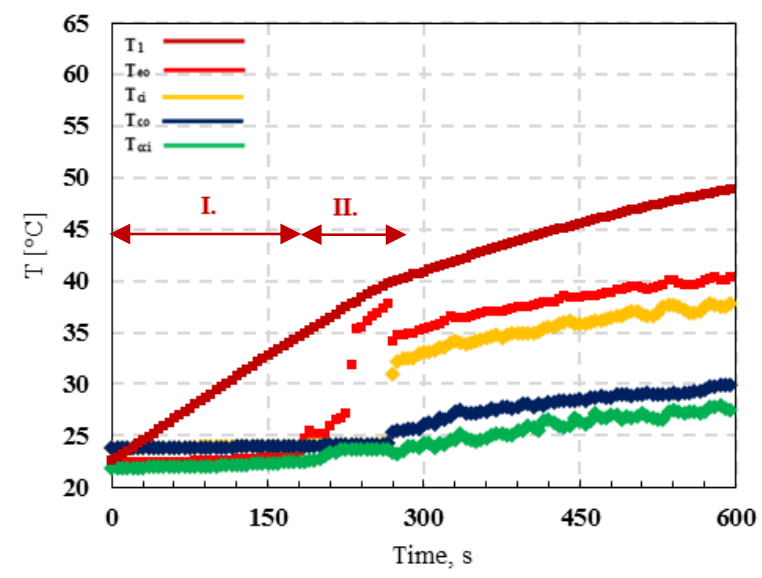

Figure 5. Startup of LHP when heating power was $125 \mathrm{~W}$

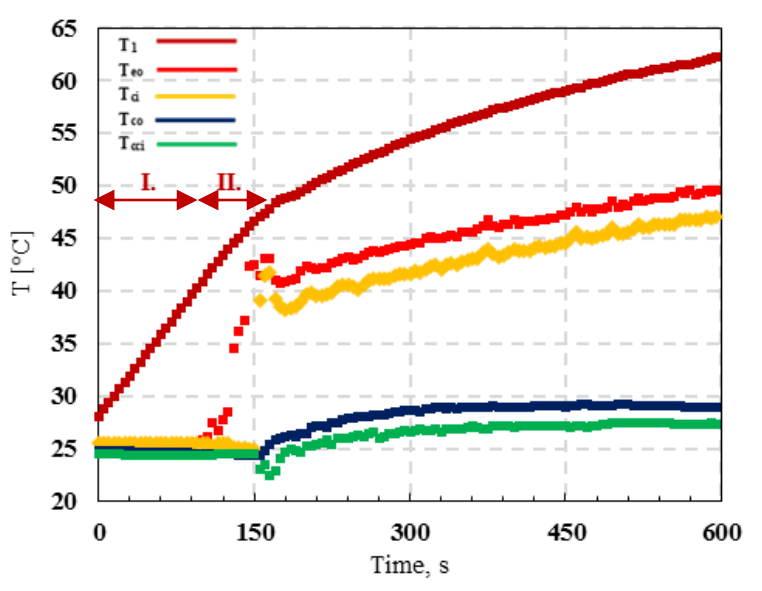

Figure 6. Startup of LHP when heating power was $270 \mathrm{~W}$ 


\subsection{Change of operating temperatures with the heat load}

Figure 7 demonstrates the dependence of temperatures on the heating block's top surface $T_{s l}$, outlet of evaporator $T_{e o}$, inlet of condenser $T_{c i}$, outlet of condenser $T_{c o}$ and inlet of compensation chamber $T_{c c i}$ on the heating power $Q$. Firstly, during the whole range of $Q$, the relation of $T_{s l}, T_{e o}$ with heating power is nearly linear. At every certain heat load, $T_{e o}$ and $T_{c i}$ existed almost at the same values while $T_{c o}$ and $T_{c c i}$ were nearly equal together. This result confirms the stable circulation of working fluid existing inside the loop. The difference between $T_{e o}$ and $T_{c i}$ became smaller with the increase of the heating power. It can be explained because the high heating power made the pressure inside the evaporator increase, so the slope of saturation line $(\mathrm{dP} / \mathrm{dT})$ would be higher or the difference in saturation temperature because of pressure drop becomes smaller. In this experiment, $T_{s l}$ can be regarded as the electronics temperature which is commonly recommended to be lower than $85^{\circ} \mathrm{C}$ for the reliable and effective operating condition [2]. The present LHP could satisfy this condition until the heating power reaches the value $350 \mathrm{~W}$. In addition, the stable increasing of $T_{s l}$ in the range of heating power from $50 \mathrm{~W}$ to $520 \mathrm{~W}$ indicated that there was no sign of dry-out existing inside the evaporator in this experiment.

\subsection{Change of thermal resistances with heating power}

Figure 8 shows the relations between total thermal resistance $R_{t}$, evaporator thermal resistance $R_{e}$, condenser thermal resistance $R_{c}$ and contact thermal resistance $R_{c t}$ with the heating power.

In general, both of total thermal resistance $R_{t}$ and evaporator resistance $R_{e}$ decreased when the heating power increased; however, they reduced significantly when heating power increased from $50 \mathrm{~W}$ to $150 \mathrm{~W}$. Under low heating power operational condition, it could be difficult for boiling to happen, so heat leakage through the wick body to the compensation chamber became significant. This kind of heat leakage could prevent the circulation or cause the total thermal resistance became higher. Consequently, the minimum value of $R_{t}$ and $R_{c}$ were $0.149 \mathrm{~K} / \mathrm{W}$ and $0.0036 \mathrm{~K} / \mathrm{W}$ respectively when heating power had value $520 \mathrm{~W}$. On the other hand, condenser thermal resistance reduced to the minimum value when heating power was around $160 \mathrm{~W}$, then raised up slightly. By observing the state of compensation chamber, this result could be explained based upon the liquid distribution inside the LHP. The higher heating power was supplied to LHP, the less liquid presented inside compensation chamber or there was more liquid phase inside the condenser; as a result, performance of condenser slightly reduces. In this experiment, the thermal contact resistance $R_{c t}$ had the average value 0.07 $\mathrm{K} / \mathrm{W}$ and changed between $0.005 \mathrm{~K} / \mathrm{W}$ to $0.01 \mathrm{~K} / \mathrm{W}$. The next section explains detailly about the performance of evaporator under various heat flux condition.

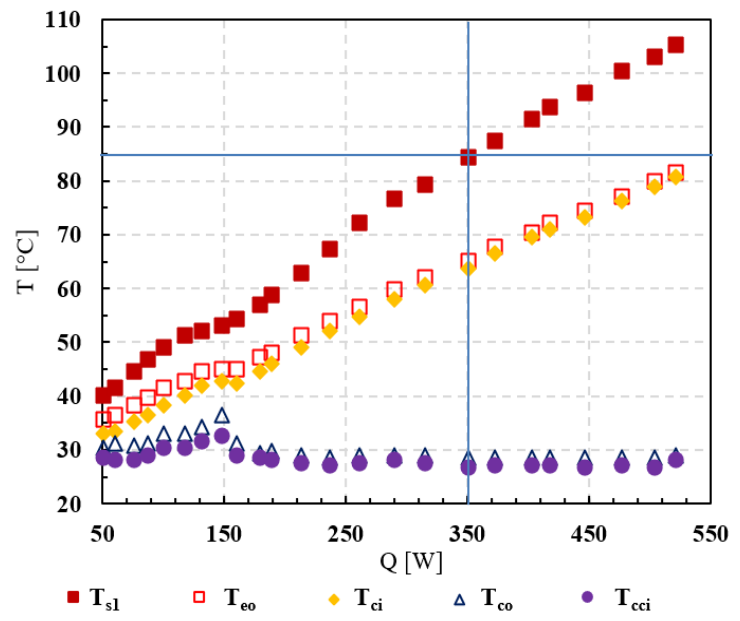

Figure 7. Changing of temperatures at different positions in experiment on heating power

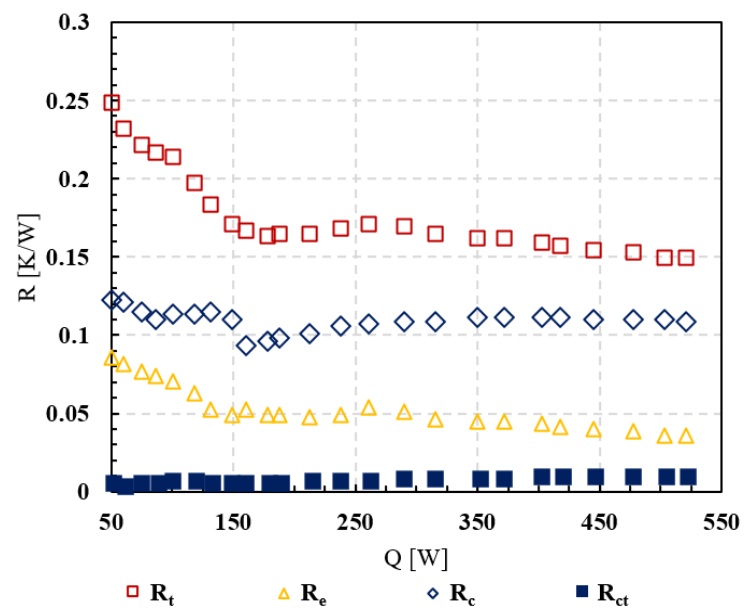

Figure 8. Changing of different thermal resistances on heating power

\subsection{Evaporator heat transfer coefficient $h_{e}$ and the assumption about boiling heat transfer phenomenon inside evaporator}

Figure 9 demonstrates the change of evaporator heat transfer coefficient $h_{e}$ with heat flux, and Figure 10 does the change of heat flux with super heat degree. To evaluate the performance of this evaporator with the bare surface, the experiment results were compared with calculational results that is estimated by Rohsenow correlation whose obtained results can be in error by $\pm 30 \%$ for superheat degree for a given heat flow rate [12]. In general, both of experimental and calculational results almost increased with the increase of heat flux. However, while the calculational results raised up nearly linearly with the flux, the changing of experiment results was different with various heat flux ranges. Firstly, when heat flux is smaller than $50 \mathrm{~kW} / \mathrm{m}^{2}$, the relation between $h_{e}$ and heat flux was almost linear. In the range of heat flux from $50 \mathrm{~kW} / \mathrm{m}^{2}$ to $100 \mathrm{~kW} / \mathrm{m}^{2}$, the values of $h_{e}$ was almost constant or changed slightly. Continuing increasing heat flux made the relation become linear again. In addition, the experimental results were only higher than calculational results when heat flux is lower than $100 \mathrm{~kW} / \mathrm{m}^{2}$. 


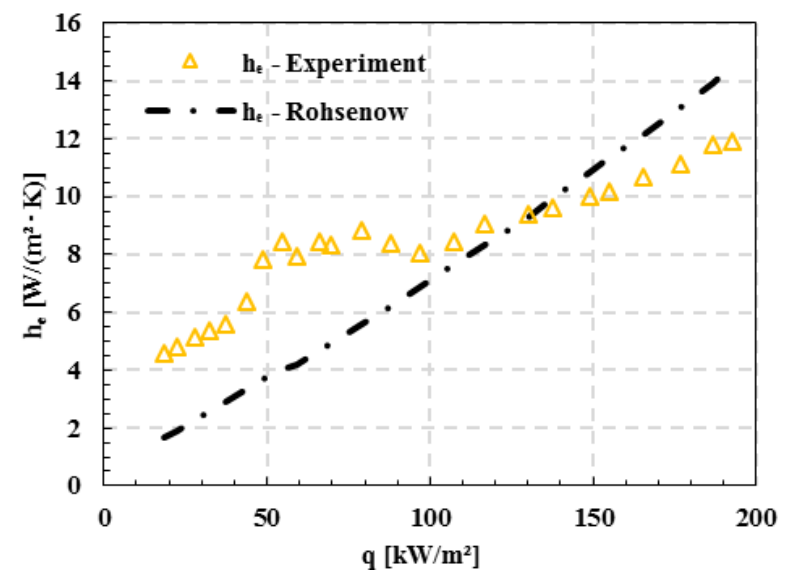

Figure 9. Relation between heat flux and evaporator heat transfer coefficient determined from experiment and Rohsenow correlation

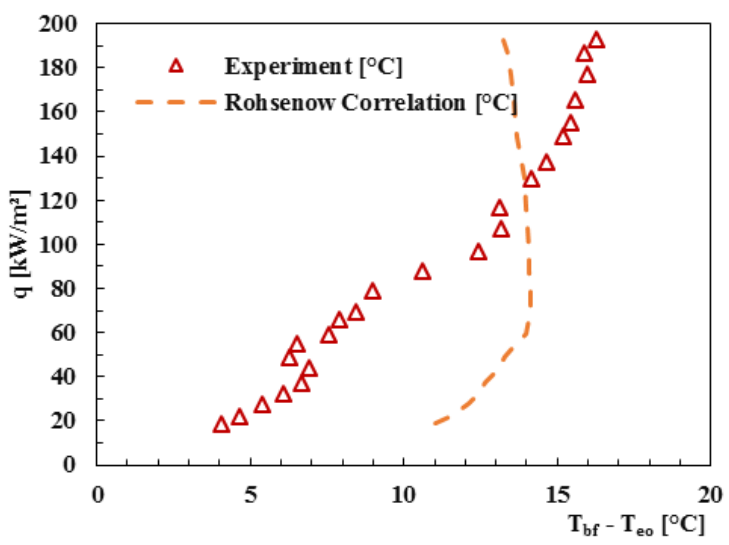

Figure 10. Relation between heat flux and superheat degree determined from experiment and Rohsenow correlation

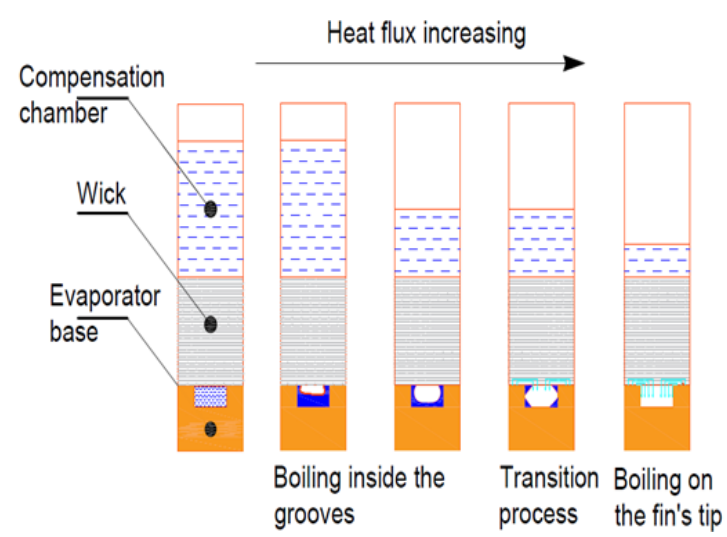

Figure 11. Assumption about boiling phenomenon under different heat flux

To explain the about results, an assumption about boiling heat transfer described in Fig. 11 was supposed in this study. Under low heat flux condition, the combination between small evaporation rate and more liquid existing inside evaporator or the liquid flooding the vapor grooves that made vapor flow out evaporator difficultly. This was also the reason which causes the heat leakage as well as total resistance $R_{t}$ to be larger in this situation. When increasing heat load, the liquid existing at the vapor grooves became less, the liquid-vapor interface area become larger that helped vapor escape evaporator more easily. On the other hand, when compared with the results from Rohsenow correlation, the experimental results had the higher values. It could be explained because the array of fins on the inner surface of evaporator increased the heat transfer area from the solid base to the liquid; as a result, enhanced the heat transfer coefficient under this situation. When heat flux was more than $50 \mathrm{~kW} / \mathrm{m}^{2}$, less liquid existing inside the grooves caused the liquid-vapor interface surface insufficient with heat input; therefore, a fraction of heat input would serve for boiling inside the grooves, the rest fraction must transfer through the fins to make boiling happen on contact surface between the fins and wick body, but this boiling now was not too active. It explains why within this range of heat flux, $\mathrm{h}_{\mathrm{e}}$ was almost constant with heat flux. Keeping on increasing heat flux more than $100 \mathrm{~kW} / \mathrm{m}^{2}$, nucleate boiling would happen efficiently on the fin's tip surface; hence, heat transfer coefficient $h_{e}$ increased proportionally with heat flux again. On the contrary, within this range of heat flux, the results obtained from Rohsenow correlation became higher than experiment. From the above assumption, when heat flux was higher than $100 \mathrm{~kW} / \mathrm{m}^{2}$, the boiling happens almost on the tip surface of the fins. It means that the height of the fins might cause the evaporator thermal resistance increase.

Besides, the change of boiling from inside the grooves to on the contact surface tip of the fins also reduces the area for boiling. Two above explanations could be the reasons why the evaporator heat transfer coefficient determined from experiment had the lower values than from correlation in the range of heat flux being larger than $100 \mathrm{~kW} / \mathrm{m}^{2}$. In summary, under small heat flux, the liquid-vapor interface presents inside vapor grooves and expands its area with heat flux value. Keeping heat flux increasing can clear all liquid inside vapor grooves and cause the liquid-vapor interface to move to the contact surface between wick and evaporator body. The above results also show that it is necessary to conduct the study on finding the optimal size of the fin to improve the performance of the evaporator when functioning under high heat flux situation.

\subsection{Cooling performance under no heating power condition}

This experiment was carried out after the stable operation of LHP. Figure 12 demonstrates the change of temperature $T_{1}, T_{e o}, T_{c i}, T_{c o}, T_{c c i}$ after turning heaters off. It took about 15 minutes to reduce the $T_{1}$ from $102{ }^{\circ} \mathrm{C}$ to $37^{\circ} \mathrm{C}$, then value of $T_{l}$ almost constant. The cooling rate reduced with time. During the first five minutes, the average cooling rate was around $8.12{ }^{\circ} \mathrm{C} / \mathrm{min}$ and decreased to $3.83{ }^{\circ} \mathrm{C} / \mathrm{min}$ during the next five minutes and finally was $1.15^{\circ} \mathrm{C} / \mathrm{min}$. When $T_{l}$ had value $37.6{ }^{\circ} \mathrm{C}, T_{c i}$ dropped suddenly far from $T_{e o}$ or the circulation stopped. $T_{e o}$ did not reduce, that indicates the evaporation still happened, but the heat released from heater was not strong enough to maintain the circulation. 


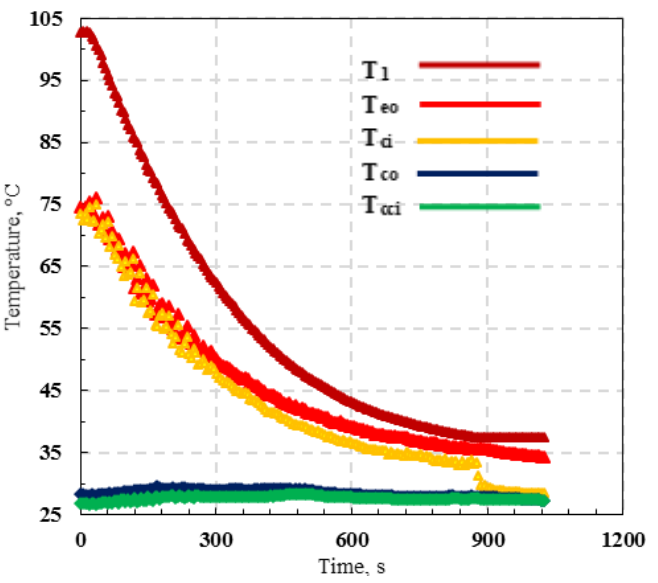

Figure 12. The cooling performance of the present loop heat pipe when heaters were turn off

\section{Conclusion}

In this study, a LHP with flat-rectangular evaporator was manufactured and investigated performance under gravity assisted condition in the range of heating power from $50 \mathrm{~W}$ to $520 \mathrm{~W}$. The time for the present LHP to startup reduced from 12 mins to 2.5 mins when heating power increased from $50 \mathrm{~W}$ to $270 \mathrm{~W}$. The flooding situation at the vapor line could be the reason that caused the startup to be longer and the appearance of temperature overshoot at the end of startup under low heating power condition.

The present LHP could maintain temperature on top surface of the heating block below $85^{\circ} \mathrm{C}$, which is the commonly suggested limitation value for the safe and effective operation, when heating power was smaller than $350 \mathrm{~W}$. Besides, it kept the stable operational performance on the whole range of heating power without the sign of dryout inside evaporator.

In general, both of total thermal resistance $R_{t}$ and thermal resistance of evaporator $R_{e}$ became smaller with the increase of heating power. Consequently, $R_{t}$ and $R_{e}$ had the minimum values $0.149 \mathrm{~K} / \mathrm{W}$ and $0.0036 \mathrm{~K} / \mathrm{W}$ respectively when heating power was at $520 \mathrm{~W}$. The thermal contact resistance $R_{c t}$ had maximum value $0.01 \mathrm{~K} / \mathrm{W}$.

In addition, an assumption of boiling heat transfer was introduced in this study for explaining the change of the evaporator heat transfer coefficient of the present LHP with heat flux. At small heat flux, the liquid-vapor interface formed inside vapor grooves and gains its surface area with heat flux. When heat flux had value more than $100 \mathrm{~kW} / \mathrm{m}^{2}$, it presented at the contact surface between fin and wick body. Evaporator heat transfer coefficient $h_{e}$ was almost constant with heat flux during transition process, where heat flux is from $50 \mathrm{~kW} / \mathrm{m}^{2}$ to $100 \mathrm{~kW} / \mathrm{m}^{2}$.

With the 4.36-kg copper heating block, under no heating power condition, it took about 15 minutes to reduce the temperature $T_{l}$ inside the heating block from $102{ }^{\circ} \mathrm{C}$ to 37 ${ }^{\circ} \mathrm{C}$ with the max cooling rate that was $8.12{ }^{\circ} \mathrm{C} / \mathrm{min}$ in the first five minutes of cooling period.

\section{Nomenclature}

$\begin{array}{lll}A & : & \text { area of the top surafce of the heating block, } \mathrm{m}^{2} \\ c_{\mathrm{p}} & : & \text { specific heat of cooling water, } \mathrm{J} /(\mathrm{kgK}) \\ h_{\mathrm{e}} & : & \text { evaporator heat transfer coefficient, } \mathrm{kW} /\left(\mathrm{m}^{2} \mathrm{~K}\right) \\ I D / O D & : & \text { pipe inner, outer diameter, } \mathrm{mm} \\ k & : & \text { copper thermal conductivity, } \mathrm{W} /(\mathrm{m} \cdot \mathrm{K}) \\ m_{\text {wa }} & : & \text { cooling water mass flow rate, } \mathrm{kg} / \mathrm{s} \\ q & : & \text { heat flux, } \mathrm{kW} / \mathrm{m}^{2} \\ Q & : & \text { heat load, } \mathrm{W} \\ Q_{\mathrm{c}} & : & \text { heat released from condenser, } \mathrm{W} \\ R_{\mathrm{t}}, & : & \text { total thermal resistance, } \mathrm{K} / \mathrm{W} \\ R_{\mathrm{e}} & : & \text { evaporator thermal resistance, } \mathrm{K} / \mathrm{W} \\ R_{\mathrm{c},} & : & \text { condenser thermal resistance, } \mathrm{K} / \mathrm{W} \\ R_{\mathrm{ct}} & : & \text { thermal contact resistance, } \mathrm{K} / \mathrm{W} \\ T_{1} t o T_{3} & : & \text { heater temperature, },{ }^{\circ} \mathrm{C} \\ T_{4} & : & \text { evaporator base temperature, },{ }^{\circ} \mathrm{C} \\ T_{\mathrm{a}} & : & \text { room temperature, },{ }^{\circ} \mathrm{C} \\ T_{\mathrm{bf}} & : & \text { temperature at the base of fin, },{ }^{\circ} \mathrm{C} \\ T_{\mathrm{ci}} & : & \text { temperature at condenser inlet, }{ }^{\circ} \mathrm{C} \\ T_{\mathrm{co}} & : & \text { temperature at condenser outlet, }{ }^{\circ} \mathrm{C} \\ T_{\mathrm{cci}} & : & \text { temperature at compensation chamber inlet, }{ }^{\circ} \mathrm{C} \\ T_{\mathrm{eo}} & : & \text { temperature at evaporator outlet, }{ }^{\circ} \mathrm{C} \\ T_{\mathrm{s} 1} & : & \text { temperature at heater surface, },{ }^{\circ} \mathrm{C} \\ T_{\mathrm{s} 2} & : & \text { temperature at evaporator bottom surface, }{ }^{\circ} \mathrm{C} \\ T_{\text {wa-i }} & : & \text { temperature of cooling water at inlet position, }{ }^{\circ} \mathrm{C} \\ T_{\text {wa-o }} & : & \text { temperature of cooling water at outlet position, }{ }^{\circ} \mathrm{C} \\ \delta_{1} & : & \text { distance between the thermocouples inside heating block } \\ \delta_{2} & : & \text { distance between the thermocouple } T_{4} \text { and the bottom } \\ & & \text { surface of evaporator } \\ & & \end{array}$

\section{References}

[1] S. M. Sohel Murshed and C. A. Nieto de Castro, A critical review of traditional and emerging techniques and fluids for electronics cooling, Renew. Sustain. Energy Rev. 2017, 78, pp.821-833.

[2] K. Ebrahimi, G. F. Jones, and A. S. Fleischer, A review of data center cooling technology, operating conditions and the corresponding lowgrade waste heat recovery opportunities, Renew. Sustain. Energy Rev.2014, pp.622-638.

[3] A. C. Kheirabadi and D. Groulx, Cooling of server electronics: A design review of existing technology, Appl. Therm. Eng. 2016, 105, pp. 622-638.

[4] Y. F. Maydanik, Loop heat pipes, Appl. Therm. Eng. 2005, 25, pp. 635-657

[5] J. Li, D. Wang, and G. P. Peterson, Experimental studies on a high performance compact loop heat pipe with a square flat evaporator, Appl. Therm. Eng. 2010, 30, pp.741-752.

[6] J. Xu, Z. Wang, H. Xu, and L. Zhang, Experimental research on the heat performance of a flat copper-water loop heat pipe with different inventories, Exp. Therm. Fluid Sci. 2017, 84, pp.110-119.

[7] G. Zhou and J. Li, Two-phase flow characteristics of a high performance loop heat pipe with flat evaporator under gravity, Intl. Journal of Heat and Mass Transfer 2018, 117, pp.1063-1074.

[8] A. Suzuki, K. Sato, Y. Koito, and T. Tomimura, Prototype Experiment on Cooling Performance of a JEST-type Loop Heat Pipe, 4th World Conf. Appl. Sci. Eng. Technol. 2015, pp.24-27.

[9] C. Kondou, S. Umemoto, S. Koyama, Y. Mitooka, Improving the heat dissipation performance of a looped thermosyphon using low-GWP volatile fluids R1234ze(Z) and R1234ze(E) with a super-hydrophilic boiling surface, Appl. Therm. Eng. 2017, 118, pp.147-158.

[10] H. He, K. Furusato, M. Yamada, B. Shen, and S. Hidaka, Efficiency enhancement of a loop thermosyphon on a mixed-wettability evaporator surface, Appl. Therm. Eng. 2017, 123, pp.1245-1254.

[11] SMC Coporation, Sintered metal element (EB/ES Series), pp.103118.

[12] A. J. G. Yunus A. Cengel, Heat and Mass Transfer: Fundamental \& Application, 5th ed. Mc Graw Hill, 2014, p.602. 